\title{
Time trend of medical economic outcomes of endoscopic submucosal dissection for gastric cancer in Japan: a national database analysis
}

\author{
Atsuhiko Murata $\cdot$ Kohji Okamoto • \\ Keiji Muramatsu $\cdot$ Shinya Matsuda
}

Received: 30 April 2013/ Accepted: 13 June 2013/Published online: 26 June 2013

(C) The International Gastric Cancer Association and The Japanese Gastric Cancer Association 2013

\begin{abstract}
Background Little information is available on the analysis of chronological changes in medical economic outcomes of endoscopic submucosal dissection (ESD) for gastric cancer. This study aimed to investigate the recent time trend of medical economic outcomes of ESD for gastric cancer based on the Japanese administrative database.

Methods A total of 32,943 patients treated with ESD for gastric cancer were referred to 907 hospitals from 2009 to 2011 in Japan. We collected patients' data from the administrative database to compare ESD-related complications, risk-adjusted length of stay (LOS), and medical costs during hospitalization. The study periods were categorized into three groups: $2009(n=9,727), 2010$ $(n=11,052)$, and $2011(n=12,164)$.

Results No significant difference was observed in ESDrelated complications between three study periods ( $p=0.496)$. However, mean LOS and medical costs during hospitalization of patients with ESD were significantly lower in 2011 than in 2009 and $2010(p<0.001)$. Multiple linear regression analysis showed that patients who received ESD in 2011 had a significantly shorter LOS and lower medical costs during hospitalization compared with those in 2009. The unstandardized coefficient of patients
\end{abstract}

A. Murata $(\square) \cdot$ K. Muramatsu $\cdot$ S. Matsuda

Department of Preventive Medicine and Community Health,

School of Medicine, University of Occupational and

Environmental Health, 1-1 Iseigaoka, Yahatanishi-ku,

Kitakyushu 807-8555, Japan

e-mail: amurata@med.uoeh-u.ac.jp

K. Okamoto

Department of Surgery, Yahata Municipal Hospital,

Kitakyushu, Japan with ESD in 2011 for LOS was -0.78 days [95 \% confidence interval (CI), -0.89 to $-0.65 ; p \leq 0.001]$, while that of those for medical costs during hospitalization was -290.5 US dollars (95 \% CI, -392.3 to $-188.8 ; p \leq 0.001$ ). Conclusions This study showed that the complication rate of ESD was stable, whereas the LOS and medical costs of patients were significantly reduced from 2009 to 2011.

Keywords Gastric cancer - Endoscopic submucosal dissection - Chronological change - Medical economic outcomes $\cdot$ Administrative database

\section{Introduction}

Gastric cancer is one of the most common cancers and frequent causes of cancer-related deaths in Japan [1]. According to the vital statistics released by the Ministry of Health, Welfare, and Labour in Japan, approximately 50,000 Japanese men and women die from gastric cancer annually, representing approximately $15 \%$ of annual cancer-related deaths over the past 4 decades [2]. However, the 5-year cancer survival rate in the early stage of gastric cancer has been reported to be greater than $90 \%$ in Japan $[3,4]$. Therefore, health-care policies for gastric cancer are increasingly focused on detection and treatment in the early stage [4].

Recent advances in endoscopic therapies have enabled more effective resection of early gastric cancer. Endoscopic submucosal dissection (ESD) is a promising technique for the treatment of early gastric cancer, and this endoscopic procedure allows larger en bloc resection of lesions compared with endoscopic mucosal resection (EMR) [5]. Although ESD has higher procedure-related bleeding and perforation rates compared with EMR in the 
introduction of ESD, recent studies have reported that ESD is a safe and effective method for the management of early gastric cancer [6-10]. Currently, ESD is established as the standard endoscopic treatment for early gastric cancer in Japan, as well as in some developed countries $[9,10]$.

However, no reports have evaluated the medical economic outcomes of ESD for gastric cancer. In particular, no recent time trend analyses have been performed considering medical economic outcomes based on an administrative database. Confirmation of chronological changes in medical economic outcomes of ESD for gastric cancer could be useful for studies on treatments for gastric cancer.

In this study, we investigated the recent time trend of medical economic outcomes of ESD for gastric cancer. We used a national administrative database developed for Japanese case-mix projects based on the Diagnosis Procedure Combination (DPC) system.

\section{Methods}

The DPC system and database

In Japan, the health-care system has severe financial issues due to expensive advances in medical technology, a rapidly aging society, and extended patient hospitalization [11]. To address these issues, the Ministry of Health, Labour and Welfare and its affiliated research institute have begun investigating whether the Japanese case-mix classification system can be used to standardize medical profiling and payment [11]. This has resulted in Japanese case-mix projects based on the DPC system being introduced to 82 academic hospitals (the National Cancer Center, the National Cardiovascular Center, and 80 university hospitals) in 2003 [12, 13]. Reimbursement of insurance by the DPC system is common practice in Japan. The number of acute care hospitals has increased in the administrative database of the DPC system $[12,13]$.

Each patient's financial data, claim information, and discharge summary, which includes principal diagnosis, complications, and comorbidities during hospitalization, are recorded in the administrative database of the DPC system. These data are coded in the International Classification of Diseases and Injuries 10th Revision (ICD-10th) code. Additionally, this administrative database comprises comprehensive medical information, including all interventional or surgical procedures, medications including prescribed drugs, and some devices that have been indexed in the original Japanese code [13, 14]. The Ministry of Health, Labour, and Welfare of Japan assigns these codes [11-14]. The administrative database of the DPC system contains total medical costs, which include all prices for every completed procedure. These costs are obtained using a standardized fee-for-service payment system and are recorded in the nationally uniform fee table [13, 14].

Study setting

We selected 32,943 patients treated with ESD for gastric cancer in 907 DPC participation hospitals from 2009 to 2011. These hospitals are dispersed throughout Japan and play leading roles in providing acute care medicine, advancing medical research, and educating students and medical residents [11-14]. For the present analysis, study periods were categorized into three groups according to year: $2009(n=9,727), 2010(n=11,052)$, and 2011 $(n=12,164)$.

The use of DPC data was permitted by all institutions and hospitals that provided detailed data. The research protocol of the study was approved by the ethics committee of medical care and research of the University of Occupational and Environmental Health, Kitakyushu, Japan.

Study variables

We collected data in the administrative database with regard to the clinical characteristics of hospitals and patients as follows: hospital status and region, site of cancer, age, sex, presence of chronic comorbid conditions, use of a proton pump inhibitor (PPI) and anticoagulation and antiplatelet drugs before and after ESD, ESD-related complications, length of stay (LOS), and medical costs during hospitalization.

Hospital size was categorized into three groups according to the number of hospital beds: small sized ( $<200$ beds) medium sized ( $200-600$ beds), and large sized ( $>600$ beds) [14]. Hospital regions were divided into eight categories: Hokkaido, Tohoku, Kanto, Chubu, Kinki, Chugoku, Shikoku, and Kyusyu regions. The site of cancer was defined using the ICD-10th code: C16.0 (cardia), C16.1 (fundus), C16.2 (body), C16.3 (antrum), C16.4 (pylorus), and C16.5, C16.6, C16.8, and C16.9 (unknown category). Age was stratified into three groups: younger than 60 years, $60-80$ years, and older than 80 years, as in a previous report [15]. The severity of chronic comorbid conditions was assessed using the Charlson Comorbidity Index (CCI), which is widely used for recording comorbidities and has been validated in various studies [16]. The CCI score was calculated for each patient as in previous studies, and this demonstrates the association between the CCI and ICD-10th code [17]. The CCI score was expressed as the score of all comorbid conditions, and it was initially evaluated as a continuous variable. However, categorical variables defining three categories of severity of chronic comorbid conditions were created to simplify the presentation of the results: 0 , mild; 1 , moderate; 2 or higher, 
severe [11-14]. ESD-related complications were defined as any of the following ICD-10 codes: perforation of the stomach (K25.5), peritonitis (K65.0), gastrointestinal hemorrhage (K92.2), bleeding or hematoma (T81.0), and iatrogenic perforation during endoscopic procedures (T81.2). These complications were defined according to published criteria [18-20]. For the analysis of medical costs during hospitalization, we assumed the yen to dollar exchange rate to be approximately 90 yen to the US dollar (February 2013).

\section{Statistical analysis}

We used the chi-squared test for categorical data and oneway factorial analysis of variance (ANOVA) for continuous variables. We used simple and multiple logistic regression models to estimate the odds ratios (ORs) and their $95 \%$ confidence intervals (CIs) for ESD-related complications, with the 2009 group considered as the reference group. To control for selection bias with regard to baseline characteristics of patients between fiscal years, we performed generalized propensity score analysis to estimate the dose-response function for each year. The propensity score method has been widely used in observational studies to deal with possible biases [21, 22]. We used a multinomial logistic regression model with logit as the link function to obtain generalized propensity scores using the data of patient characteristics, such as the site of cancer, age, sex, presence of chronic comorbid conditions, and use of a PPI and anticoagulation and antiplatelet drugs. Robust standard errors were also used to allow for the effect of clustering of patients within hospitals. In additional analyses, multiple linear regression models were used to identify the effect of chronological changes on LOS and medical costs during hospitalization, considering hospital characteristic and propensity scores.

All statistical analyses were performed using the STATA statistical software package version 11.0 (Stata Corp., College Station, TX, USA). A value of $p<0.05$ was considered significant.

\section{Results}

A total of 32,943 patients with ESD for gastric cancer were identified for this study, comprising 9,727 patients in 2009 , 11,052 patients in 2010 , and 12,164 patients in 2011 . The total rate of complications related to ESD was $3.4 \%$ from 2009 to 2011. The total mean LOS of all patients was 9.9 days, and the mean medical cost during hospitalization was 6,555.1 US dollars.

The clinical characteristics and presentations of hospitals and patients are shown in Table 1. The proportion of hospitals where ESD was performed was highest in the Kanto region in 2009-2011 ( $p<0.001)$. With regard to the characteristics of the patients, the body of the stomach had the highest rate for performance of ESD from 2009 to 2011. The frequency of use of PPIs was lowest in 2011, whereas that of anticoagulation or antiplatelet drugs was highest in 2009. There were no significant differences in ESD-related complications from 2009 to 2011 (3.2\% in 2009 vs. $3.5 \%$ in 2010 vs. $3.3 \%$ in $2011 ; p=0.496$ ). However, mean LOS was significantly lower in 2011 than in 2009 and 2010 (10.5 days in 2009 vs. 9.8 days in 2010 vs. 9.5 days in 2011; $p<0.001)$. The mean medical cost during hospitalization was also lower in accordance with the period.

Logistic regression analysis for ESD-related complications is shown in Table 2. Simple logistic regression analysis showed that the period did not affect ESD-related complications (OR of 2010, 1.09, $95 \%$ CI, 0.93-1.26, $p=0.261$; OR of $2011,1.02,95 \%$ CI, 0.88-1.19, $p=0.751)$. After adjustment for patients' characteristics, as well as hospital status and geographic region, no significant association of the period was observed for ESDrelated complications (OR of 2010, 1.10, $95 \% \mathrm{CI}$, $0.94-1.28, \quad p=0.218$; OR of $2011,1.04,95 \% \mathrm{CI}$, $0.89-1.21, p=0.600)$.

Regarding LOS of patients with ESD, simple linear regression analysis showed that the period significantly affected the LOS. After adjustment for potentially confounding demographic and clinical variables, the period was significantly associated with decreasing LOS in patients with ESD. The unstandardized coefficient of 2010 was -0.59 days $(95 \% \mathrm{CI},-0.71$ to $-0.47, p<0.001)$ and that of 2011 was -0.78 days $(95 \% \mathrm{CI},-0.89$ to -0.65 , $p<0.001$; Table 3).

Linear regression analysis for medical costs during hospitalization of patients with ESD is shown in Table 4. There was a consistently significant association between the period and medical costs during hospitalization. Multivariate regression analysis showed that the period was significantly associated with decreasing medical costs in patients with ESD. The unstandardized coefficient of 2010 was -261.5 US dollars (95\% CI, -362.2 to -160.8 , $p<0.001)$ and that of 2011 was -290.5 US dollars (95\% CI, -392.3 to $-188.8, p<0.001)$.

\section{Discussion}

We investigated the recent time trend analysis of medical economics outcomes of ESD for gastric cancer using a national administrative database. We found no significant difference with regard to ESD-related complications, while LOS and medical costs of patients with ESD for 
Table 1 Clinical characteristics of the hospitals and patients with endoscopic submucosal dissection for gastric cancer

\begin{tabular}{|c|c|c|c|c|c|}
\hline \multirow{2}{*}{$\begin{array}{l}\text { Table } 1 \text { Clinical characteristics } \\
\text { of the hospitals and patients } \\
\text { with endoscopic submucosal } \\
\text { dissection for gastric cancer }\end{array}$} & & $\begin{array}{l}2009 \text { year } \\
(n=9,727)\end{array}$ & $\begin{array}{l}2010 \text { year } \\
(n=11,052)\end{array}$ & $\begin{array}{l}2011 \text { year } \\
(n=12,164)\end{array}$ & $p$ value \\
\hline & \multicolumn{5}{|l|}{ Hospital characteristics } \\
\hline & \multicolumn{5}{|l|}{ Hospital size (\%) } \\
\hline & Small sized & 34.0 & 34.3 & 41.5 & \multirow[t]{3}{*}{$<0.001$} \\
\hline & Medium sized & 42.4 & 36.4 & 32.9 & \\
\hline & Large sized & 23.6 & 29.3 & 25.6 & \\
\hline & \multicolumn{5}{|l|}{ Hospital region $(\%)$} \\
\hline & Hokkaido region & 2.7 & 2.6 & 2.9 & \multirow[t]{8}{*}{$<0.001$} \\
\hline & Tohoku region & 12.4 & 9.7 & 7.4 & \\
\hline & Kanto region & 23.2 & 26.8 & 27.9 & \\
\hline & Chubu region & 17.8 & 17.3 & 17.8 & \\
\hline & Kinki region & 18.1 & 19.0 & 19.2 & \\
\hline & Chugoku region & 7.3 & 8.0 & 9.0 & \\
\hline & Shikoku region & 3.1 & 2.7 & 3.5 & \\
\hline & Kyusyu region & 15.4 & 13.9 & 12.3 & \\
\hline & \multicolumn{5}{|l|}{ Patient characteristics } \\
\hline & \multicolumn{5}{|l|}{ Site of gastric cancer $(\%)$} \\
\hline & Cardia & 5.5 & 6.1 & 6.0 & \multirow[t]{6}{*}{0.003} \\
\hline & Fundus & 1.5 & 1.5 & 1.6 & \\
\hline & Body & 44.8 & 44.2 & 45.7 & \\
\hline & Antrum & 27.5 & 26.1 & 26.5 & \\
\hline & Pylorus & 3.9 & 4.2 & 4.2 & \\
\hline & Unknown category & 16.8 & 17.9 & 16.0 & \\
\hline & \multicolumn{5}{|l|}{ Age } \\
\hline & Mean age (years) & 72.1 & 71.5 & 71.7 & 0.003 \\
\hline & \multicolumn{5}{|l|}{ Age categories $(\%)$} \\
\hline & $<60$ years & 9.2 & 9.8 & 8.6 & \multirow[t]{3}{*}{$<0.001$} \\
\hline & $60-80$ years & 72.3 & 74.8 & 74.8 & \\
\hline & $>80$ years & 18.5 & 15.4 & 16.6 & \\
\hline & \multicolumn{5}{|l|}{$\operatorname{Sex}(\%)$} \\
\hline & Male & 73.9 & 74.1 & 74.3 & \multirow[t]{2}{*}{0.757} \\
\hline & Female & 26.1 & 25.9 & 25.7 & \\
\hline & \multicolumn{5}{|l|}{ Chronic comorbid conditions (\%) } \\
\hline & Mild & 47.4 & 43.9 & 41.3 & \multirow[t]{3}{*}{$<0.001$} \\
\hline & Moderate & 35.1 & 39.1 & 40.8 & \\
\hline & Severe & 17.5 & 17.0 & 17.9 & \\
\hline & Use of proton pump inhibitor (\%) & 97.3 & 97.3 & 94.9 & $<0.001$ \\
\hline & Use of anticoagulation drugs (\%) & 3.1 & 2.2 & 2.3 & $<0.001$ \\
\hline & Use of antiplatelet drugs (\%) & 2.8 & 2.5 & 2.2 & 0.021 \\
\hline & \multicolumn{5}{|l|}{ Outcomes } \\
\hline & ESD-related complications (\%) & 3.2 & 3.5 & 3.3 & 0.496 \\
\hline & Mean length of stay (days) & 10.5 & 9.8 & 9.5 & $<0.001$ \\
\hline $\begin{array}{l}E S D \text { endoscopic submucosal } \\
\text { dissection }\end{array}$ & Mean medical costs (US dollars) & $6,768.4$ & $6,507.7$ & $6,427.6$ & $<0.001$ \\
\hline
\end{tabular}

$E S D$ endoscopic submucosal dissection gastric cancer were significantly reduced from 2009 to 2011.

While many studies have focused on the efficacy of ESD, such as en-bloc resection or the complete resection rate for patients with gastric cancer, studies evaluating the medical economics of ESD for gastric cancer are rare.
However, evaluation of the medical economics of treatments, such as LOS or medical costs, are increasingly important because many developed countries consider that health-care providers should take into account the medical economic impact as well as the efficacy of treatment. Furthermore, determining chronological changes in 
Table 2 Logistic regression analysis for endoscopic submucosal dissection-related complications

\begin{tabular}{|c|c|c|c|}
\hline & Odds ratio & $95 \%$ confidence interval & $p$ value \\
\hline \multicolumn{4}{|c|}{ Simple logistic regression } \\
\hline 2009 & 1.00 (reference) & & \\
\hline 2010 & 1.09 & $0.93-1.26$ & 0.261 \\
\hline 2011 & 1.02 & $0.88-1.19$ & 0.751 \\
\hline \multicolumn{4}{|c|}{ Multivariate logistic regression $^{\dagger}$} \\
\hline 2009 & 1.00 (reference) & & \\
\hline 2010 & 1.10 & $0.94-1.28$ & 0.218 \\
\hline 2011 & 1.04 & $0.89-1.21$ & 0.600 \\
\hline
\end{tabular}

Table 3 Linear regression analysis for length of stay (days)

\begin{tabular}{llll}
\hline & Coefficient & $95 \%$ Confidence interval & $p$ value \\
\hline \multicolumn{2}{l}{ Simple linear regression } \\
2009 & Reference & \\
2010 & -0.64 & -0.76 to -0.52 & $<0.001$ \\
2011 & -0.95 & -1.07 to -0.83 & $<0.001$ \\
Multivariate linear regression & & \\
2009 & Reference & & $<0.001$ \\
2010 & -0.59 & -0.71 to -0.47 & $<0.001$ \\
2011 & -0.78 & -0.89 to -0.65 & \\
\hline
\end{tabular}

$\dagger$ Multivariate coefficient adjusted for hospital characteristics (hospital size and region) and propensity score (site of gastric cancer, age, sex, chronic comorbid conditions, use of proton pump inhibitor and anticoagulation and antiplatelet drugs)

Table 4 Linear regression analysis for medical costs during hospitalizations (US dollars)

\begin{tabular}{llll}
\hline & Coefficient & $95 \%$ confidence interval & $p$ value \\
\hline \multicolumn{2}{l}{ Simple linear regression } & & \\
2009 & Reference & & \\
2010 & -260.6 & -361.6 to -159.7 & $<0.001$ \\
2011 & -340.7 & -439.5 to -242.0 & $<0.001$ \\
Multivariate linear regression & & \\
2009 & Reference & & $<0.001$ \\
2010 & -261.5 & -362.2 to -160.8 & $<0.001$ \\
2011 & -290.5 & -392.3 to -188.8 &
\end{tabular}

${ }^{\dagger}$ Multivariate coefficient adjusted for hospital characteristics (hospital size and region) and propensity score (site of gastric cancer, age, sex, chronic comorbid conditions, use of proton pump inhibitor and anticoagulation and antiplatelet drugs)

medical economics could be useful information for confirming the change in quality of patient's care. The present study is the first report of a recent time trend analysis considering medical economic outcomes of ESD for gastric cancer.

With regard to the rate of ESD-related complications, we consider that the technical skill level of ESD for gastric cancer has been stable from 2009 to 2011. ESD is a technically demanding endoscopic procedure for gastric cancer. In the early 2000s, some clinical studies reported that the complication rate of ESD was from 5 to $8 \%[23,24]$. However, several recent reports showed that the complication rate of ESD ranged from 3 to $5 \%$, which was lower than in the early 2000s [25-27]. In our study, the complication rate of ESD based on an administrative database was approximately $3 \%$ from 2009 to 2011, which indicated that complications of ESD remained low. Kakushima et al. [28] reported that constant rates of treatment efficacy and complications were achieved over a 5-year period of experience with ESD for gastrointestinal neoplasms. Some recent reports have also suggested that a certain number of cases are necessary to produce skilled and competent endoscopists for ESD [29, 30]. In addition, Uedo et al. [31] pointed out that ESD is performed by more experienced endoscopists in Japan than in other Asian countries in their questionnaire survey among some Asian countries in 2011. Therefore, our results may suggest that the number of experienced endoscopists has been increasing since the early 2000s, and their technical skill level in ESD has been favorably stable from 2009 to 2011. Additionally, various types of ESD devices have been introduced recently [3234]. These new devices appear to be safer and more effective compared to those used at the introduction of ESD [33, 34]. Therefore, the development of devices for ESD may also have contributed to the decrease in complications between the early 2000s and now and to the steadiness of the ESD complication rate.

However, LOS and medical costs of patients with ESD for gastric cancer decreased significantly from 2009 to 2011. Various factors may explain the association between the period and the LOS and medical costs in patients with ESD. First, a critical path for ESD has frequently been used to improve treatment efficiency, especially in hospitals with larger case volumes. A critical path briefly summarizes the procedure or treatments that are necessary during hospitalization along the time axis. This system has contributed to the efficiency and standardization of ESD [35, 36]. In addition, the data in our study came from DPCparticipating hospitals. These hospitals have adopted a unique reimbursement system whereby the paid medical treatment fees become proportionally higher as the LOS becomes shorter [37]. Therefore, a shorter hospitalization leads to an increase in income for the hospitals. Furthermore, payment per hospitalization is strictly determined by the DPC payment system. Many hospitals have become stricter about expenses and longer hospitalizations, so that 
unnecessary expenses for drugs and ESD materials or a longer hospitalization may be reduced [37]. Therefore, the efficiency of treatment, such as using a critical path or a unique reimbursement system for payment, may have been mainly associated with a decrease in LOS or medical costs during hospitalization from 2009 to 2011. Second, many experienced endoscopists can respond quickly to the occurrence of complications; therefore, their rapid action may obscure any effect of complications on LOS in patients with ESD. In addition, some previous reports have shown that the various management strategies for ESD complications prevent the development of much more severe conditions in patients with complications [7, 18, 19, 23]. Our results also suggest that a quick response by many experienced endoscopists or the establishment of a management strategy for ESD complications as well as the efficiency of treatment might have shortened LOS, while the ESD complication rate reemained stable from 2009 to 2011.

The data used represent a major strength of the current study. One of the benefits of the national database was that it enabled evaluation of a large number of hospitals in an unbiased manner, because our investigation involved a nationally representative sample of patients in a community setting [11-14]. In 2008, 2,120,170 hospitalization records were gathered in the administrative database of the DPC system. These data were collected from hospitals participating in the survey, and 855 out of the 1,557 hospitals agreed to participate in the survey in 2008, which represented approximately $40 \%$ of acute inpatients during that time [38]. In addition, Fushimi [39] reported that the data from the DPC database are almost consistent with actual patient data. Therefore, this administrative database also enables interested parties to evaluate outcomes with individual detailed medical treatments, and the validity and reliability of the data from the DPC database have been reasonably assured.

Some potential limitations of this study also warrant mention. First, the data were obtained from DPC participating hospitals. Our study indicated that LOS and medical costs of patients with ESD experienced similar changes between 2009 and 2011 in a parallel manner. The DPC system may play a role in this association between LOS and medical costs of patients with ESD. Therefore, data in non-DPC-participating hospitals should be analyzed to confirm the influence of the DPC system in the future. Second, we could not investigate the types of devices for ESD, such as insulation-tipped knives, hook knives, needle knives, or flex knives, and other knives or endoscopic systems, such as narrow banding imaging or carbon dioxide insufflation. The types of devices or endoscopic systems used in ESD are not recorded in the Japanese administrative database. These factors may affect the medical costs for ESD. Third, we did not evaluate readmission of patients who underwent ESD in this study. Some previous reports have suggested that delayed bleeding sometimes occurs after discharge from the hospital [40, 41]. The presence of late complications after discharge may also influence medical costs for patients with ESD. Fourth, because this administrative database does not include clinical data such as endoscopic imaging or the procedure time of ESD, we could not evaluate the lesion size of gastric cancer or procedure time of ESD in this study. Some reports have suggested that complications are significantly higher in the case of large-sized lesions or with a longer ESD procedure time [18, 42-44]. Therefore, further clinical studies evaluating time trend analysis may be required, taking into account clinical data, such as the lesion size of gastric cancer or the procedure time of ESD, and the devices or endoscopic system used for ESD for gastric cancer and readmission of patients who have undergone ESD.

In spite of these limitations, the current study has implications for the quality of patient care and future research. First, live demonstrations and symposiums to share techniques and knowledge of how to perform ESD are frequently held in Japan $[45,46]$. In addition, a training program for ESD has been introduced by some hospitals $[47,48]$. These steady efforts have favorably influenced the medical economic outcomes of ESD so that ESD will play a more important role in gastric cancer treatment in Japan. However, the total mean LOS of all patients with ESD in this study was 9.9 days, which is longer than that in reports from high-volume hospitals. Our administrative database enables the monitoring of medical economic outcomes of patients with ESD for gastric cancer because the patients' data are collected in the administrative database every year [11-14]. Therefore, the medical quality of ESD in many hospitals should be confirmed by successive monitoring based on a national administrative database. Second, important clinical data, such as en-bloc resection or the complete resection rate, are still lacking in our database, although this study demonstrated the time trend of outcomes of ESD for gastric cancer, such as ESD-related complications. The Japanese Gastric Cancer Association (JGCA) began a project to register patients who were treated by ESD in 2011 [49]. The results from the database of this project will be useful information on the quality of ESD for gastric cancer in the near future. However, we consider that more valuable information can be produced by a link between our administrative database and the database in this project. For example, the Surveillance, Epidemiology, and End Results (SEER) program of cancer registries, which is a cancer registry database in the USA, has been linked to the Medicare Claim Database known as a medical services payment system. As a result, many 
clinical studies have reported using these linked databases [50]. Therefore, we believe that a link between our database and the database of the JGCA may be vital for future research on ESD in Japan. If this is carried out, more valuable information showing the favorable quality of ESD for gastric cancer can be expected in patients who undergo ESD for gastric cancer.

In conclusion, this study demonstrated that the complication rate of ESD was stable, whereas the LOS and medical costs of patients decreased significantly from 2009 to 2011. Our results may suggest that the number of experienced endoscopists has been increasing, and the skill level of ESD has been favorably stable. Additionally, improvement in the medical economic quality of ESD for gastric cancer has also been progressing in Japan.

Acknowledgments This study was funded by Grants-in-Aid for Research on Policy Planning and Evaluation from the Ministry of Health, Labour, and Welfare, Japan.

Conflict of interest None of the authors have any conflicts of interest to declare.

\section{References}

1. Catalano V, Labianca R, Beretta GD, Gatta G, de Braud F, Van Cutsem E. Gastric cancer. Crit Rev Oncol Hematol. 2009;71:127-64

2. Lin Y, Ueda J, Kikuchi S, Totsuka Y, Wei WQ, Qiao YL, et al. Comparative epidemiology of gastric cancer between Japan and China. World J Gastroenterol. 2011;17:4421-8.

3. Kitano S, Shiraishi N, Uyama I, Sugihara K, Tanigawa N, Japanese laparoscopic surgery study group. A multicenter study on oncologic outcome of laparoscopic gastrectomy for early cancer in Japan. Ann Surg. 2007;245:68-72.

4. Uedo N, Takeuchi Y, Ishihara R. Endoscopic management of early gastric cancer: endoscopic mucosal resection or endoscopic submucosal dissection: data from a Japanese high-volume center and literature review. Ann Gastroenterol. 2012;25:1-10.

5. Oka S, Tanaka S, Kaneko I, Mouri R, Hirata M, Kawamura T, et al. Advantage of endoscopic submucosal dissection compared with EMR for early gastric cancer. Gastrointest Endosc. 2006;64:877-83.

6. Oda I, Gotoda T. Remarkable progress in endoscopic resection of early gastric cancer. J Gastroenterol Hepatol. 2009;24:1313-4.

7. Minami S, Gotoda T, Ono H, Oda I, Hamanaka H. Complete endoscopic closure using endoclips for gastric perforation during endoscopic resection for early gastric cancer can avoid emergent surgery. Gastrointest Endosc. 2006;63:596-601.

8. Ikehara H, Gotoda T, Ono H, Oda I, Saito D. Gastric perforation during endoscopic resection for gastric carcinoma and the risk of peritoneal dissemination. Br J Surg. 2007;94:992-5.

9. Akahoshi K, Akahane H, Motomura Y, Kubokawa M, Itaba S, Komori K, et al. A new approach: endoscopic submucosal dissection using the clutch Cutter ${ }^{\circledR}$ for early stage digestive tract tumors. Digestion. 2012;85:80-4.

10. Białek A, Wiechowska-Kozłowska A, Pertkiewicz J, Polkowski M, Milkiewicz P, Karpińska K, et al. Endoscopic submucosal dissection for treatment of gastric subepithelial tumors (with video). Gastrointest Endosc. 2012;75:276-86.
11. Murata A, Matsuda S, Mayumi T, Yokoe M, Kuwabara K, Ichimiya $\mathrm{Y}$, et al. A descriptive study evaluating the circumstances of medical treatment for acute pancreatitis before publication of the new JPN guidelines based on the Japanese administrative database associated with the diagnosis procedure combination system. J Hepatobiliary Pancreat Sci. 2011;18:678-83.

12. Murata A, Matsuda S, Mayumi T, Yokoe M, Kuwabara K, Ichimiya Y, et al. Effect of hospital volume on clinical outcome in patients with acute pancreatitis, based on a national administrative database. Pancreas. 2011;40:1018-23.

13. Murata A, Matsuda S, Kuwabara K, Fujino Y, Kubo T, Fujimori $\mathrm{K}$, et al. An observational study using a national administrative database to determine the impact of hospital volume on compliance with clinical practice guidelines. Med Care. 2011;49: 313-20.

14. Murata A, Matsuda S, Mayumi T, Okamoto K, Kuwabara K, Ichimiya $\mathrm{Y}$, et al. Multivariate analysis of factors influencing medical costs of acute pancreatitis hospitalizations based on a national administrative database. Dig Liver Dis. 2012;44:143-8.

15. Mannen K, Tsunada S, Hara M, Yamaguchi K, Sakata Y, Fujise $\mathrm{T}$, et al. Risk factors for complications of endoscopic submucosal dissection in gastric tumors: analysis of 478 lesions. J Gastroenterol. 2010;45:30-6.

16. Sundararajan V, Henderson T, Perry C, Muggivan A, Quan H, Ghali WA. New ICD-10 version of the Charlson comorbidity index predicted in-hospital mortality. J Clin Epidemiol. 2004;57:1288-94.

17. Quan H, Sundararajan V, Halfon P, Fong A, Burnand B, Luthi JC, et al. Coding algorithms for defining comorbidities in ICD-9CM and ICD-10 administrative data. Med Care. 2005;43:1130-9.

18. Gotoda T, Yamamoto H, Soetikno RM. Endoscopic submucosal dissection of early gastric cancer. J Gastroenterol. 2006;41: 929-42.

19. Kim YJ, Park DK. Management of complications following endoscopic submucosal dissection for gastric cancer. World $\mathrm{J}$ Gastrointest Endosc. 2011;3:67-70.

20. Lian J, Chen S, Zhang Y, Qiu F. A meta-analysis of endoscopic submucosal dissection and EMR for early gastric cancer. Gastrointest Endosc. 2012;76:763-70.

21. Feng P, Zhou XH, Zou QM, Fan MY, Li XS. Generalized propensity score for estimating the average treatment effect of multiple treatments. Stat Med. 2012;31:681-97.

22. Mazzaglia G, Ambrosioni E, Alacqua M, Filippi A, Sessa E, Immordino $\mathrm{V}$, et al. Adherence to antihypertensive medications and cardiovascular morbidity among newly diagnosed hypertensive patients. Circulation. 2009;120:1598-605.

23. Saito Y, Uraoka T, Matsuda T, Emura F, Ikehara H, Mashimo Y, et al. Endoscopic submucosal dissection for early gastric cancer: technical feasibility, operation time and complications from a large consecutive series. Dig Endosc. 2005;17:54-8.

24. Ono $\mathrm{H}$, Hasuike $\mathrm{N}$, Inui $\mathrm{T}$, Takizawa $\mathrm{K}$, Ikehara $\mathrm{H}$, Yamaguchi $\mathrm{Y}$, et al. Usefulness of a novel electrosurgical knife, the insulation-tipped diathermic knife-2, for endoscopic submucosal dissection of early gastric cancer. Gastric Cancer. 2008;11:47-52.

25. Okada K, Yamamoto Y, Kasuga A, Omae M, Kubota M, Hirasawa $\mathrm{T}$, et al. Risk factors for delayed bleeding after endoscopic submucosal dissection for gastric neoplasm. Surg Endosc. 2011;25:98-107.

26. Sugimoto T, Okamoto M, Mitsuno Y, Kondo S, Ogura K, Ohmae $\mathrm{T}$, et al. Endoscopic submucosal dissection is an effective and safe therapy for early gastric neoplasms: A multicenter feasible study. J Clin Gastroenterol. 2012;46:124-9.

27. Goto O, Fujishiro M, Oda I, Kakushima N, Yamamoto Y, Tsuji $\mathrm{Y}$, et al. A multicenter survey of the management after gastric endoscopic submucosal dissection related to postoperative bleeding. Dig Dis Sci. 2012;57:435-9. 
28. Kakushima N, Fujishiro M, Kodashima S, Muraki Y, Tateishi A, Omata M. A learning curve for endoscopic submucosal dissection of gastric epithelial neoplasms. Endoscopy. 2006;38:991-5.

29. Oda I, Odagaki T, Suzuki H, Nonaka S, Yoshinaga S. Learning curve for endoscopic submucosal dissection of early gastric cancer based on trainee experience. Dig Endosc. 2012;24: 129-32.

30. Kato M, Gromski M, Jung Y, Chuttani R, Matthes K. The learning curve for endoscopic submucosal dissection in an established experimental setting. Surg Endosc. 2013;27:154-61.

31. Uedo N, Jung HY, Fujishiro M, Lee IL, Zhou PH, Chiu PW, et al. Current situation of endoscopic submucosal dissection for superficial neoplasms in the upper digestive tract in East Asian countries: a questionnaire survey. Dig Endosc. 2012;24:124-8.

32. Kim HG, Cho JY, Bok GH, Cho WY, Kim WJ, Hong SJ, et al. A novel device for endoscopic submucosal dissection, the Fork knife. World J Gastroenterol. 2008;14:6726-32.

33. Toyonaga T, Man-I M, Fujita T, Nishino E, Ono W, Morita Y, et al. The performance of a novel ball-tipped Flush knife for endoscopic submucosal dissection: a case-control study. Aliment Pharmacol Ther. 2010;32:908-15.

34. Akahoshi K, Honda K, Motomura Y, Kubokawa M, Okamoto R, Osoegawa T, et al. Endoscopic submucosal dissection using a grasping-type scissors forceps for early gastric cancers and adenomas. Dig Endosc. 2011;23:24-9.

35. Nozue M, Maruyama T, Imamura F, Fukue M. Cost accounting for gastrectomy under critical path-the usefulness of direct accounting of personnel expenses and a guide to shortening hospital stay. Gan To Kagaku Ryoho. 2000;27:1369-74.

36. Kusaka K, Kanoya Y, Sato C. Effects of introducing a critical path method to standardize treatment and nursing for early discharge from acute psychiatry unit. J Nurs Manag. 2006;14:69-80.

37. Matsuda S, Ishikawa KB, Kuwabara K, Fujimori K, Fushimi K, Hashimoto $\mathrm{H}$. Development and use of the Japanese case-mix system. Eurohealth. 2008;14:25-30.

38. Murata A, Okamoto K, Matsuda S, Kuwabara K, Ichimiya Y, Matsuda Y, et al. The care processes for acute cholecystitis according to clinical practice guidelines based on the Japanese administrative database. Tohoku J Exp Med. 2012;227:237-44.

39. Fushimi K. Factors associated with hospital selection of inpatients analyzed by patient survey data and DPC data. Iryo To Shakai. 2010;20:211-22 (Japanese).
40. Tsuji Y, Ohata K, Ito T, Chiba H, Ohya T, Gunji T, et al. Risk factors for bleeding after endoscopic submucosal dissection for gastric lesions. World J Gastroenterol. 2010;16:2913-7.

41. Okada K, Yamamoto Y, Kasuga A, Omae M, Kubota M, Hirasawa $\mathrm{T}$, et al. Risk factors for delayed bleeding after endoscopic submucosal dissection for gastric neoplasm. Surg Endosc. 2011;25:98-107.

42. Gotoda T. Endoscopic resection of early gastric cancer. Gastric Cancer. 2007;10:1-11.

43. Ohta T, Ishihara R, Uedo N, Takeuchi Y, Nagai K, Matsui F, et al. Factors predicting perforation during endoscopic submucosal dissection for gastric cancer. Gastrointest Endosc. 2012;75:1159-65.

44. Ahn JY, Choi KD, Choi JY, Kim MY, Lee JH, Choi KS, et al. Procedure time of endoscopic submucosal dissection according to the size and location of early gastric cancers: analysis of 916 dissections performed by 4 experts. Gastrointest Endosc. 2011;73:911-6.

45. Isomoto H. Global dissemination of endoscopic submucosal dissection for early gastric cancer. Intern Med. 2010;49:251-2.

46. Goda K, Fujishiro M, Hirasawa K, et al. How to teach and learn endoscopic submucosal dissection for upper gastrointestinal neoplasm in Japan. Dig Endosc. 2012;24:136-42.

47. Tsuji Y, Ohata K, Sekiguchi M, Ito T, Chiba H, Gunji T, et al. An effective training system for endoscopic submucosal dissection of gastric neoplasm. Endoscopy. 2011;43:1033-8.

48. Yamamoto Y, Fujisaki J, Ishiyama A, Hirasawa T, Igarashi M. Current status of training for endoscopic submucosal dissection for gastric epithelial neoplasm at Cancer Institute Hospital, Japanese Foundation for Cancer Research, a famous Japanese hospital. Dig Endosc. 2012;24:148-53.

49. Nashimoto A, Akazawa K, Isobe Y, Miyashiro I, Katai H, Kodera Y, et al. Gastric cancer treated in 2002 in Japan: 2009 annual report of the JGCA nationwide registry. Gastric Cancer. 2013;16:1-27.

50. Feuer EJ, Lee M, Mariotto AB, Cronin KA, Scoppa S, Penson $\mathrm{DF}$, et al. The cancer survival query system: making survival estimates from the surveillance, epidemiology, and end results program more timely and relevant for recently diagnosed patients. Cancer. 2012;118:5652-62. 